\title{
El discurso de lo posible en las Consultas varias, morales y místicas (1728), de Francisco Ildefonso Segura
}

\author{
The Discourse of the Possible \\ in Consultas varias, morales y místicas (1728) \\ by Francisco Ildefonso Segura
}

\author{
ERIC IBARRA MONTERROSO \\ Investigador independiente \\ eric.ibarramo@gmail.com
}

RESUMEN: El propósito de este artículo es examinar y dar visibilidad a un tratado moral impreso durante la primera mitad del siglo XVIII en Puebla. El artículo propone que el texto presenta rarezas notables frente a su contexto: limita y desacredita varias formas de autoridad, busca problemáticas y polémica en lugar de repetir dogmas, rechaza la realidad sobrenatural y defiende el conocimiento empírico, comparte ideas

Palabras clave:

moral; polémica; posibilidad; duda;

voz;

razón. basadas en la duda y en la razón. El artículo argumenta que estas y otras rarezas son consecuencia de un discurso basado en las ideas de posibilidad, hipótesis y excepción, lo cual se analiza principalmente en la voz del autor y en su relación con los libros y la escritura.

KEYWORDS:

Morals;

Polemic;

Possibility;

Doubt;

Voice:

Reason.
ABSTRACT: The purpose of this article is to examine and give some visibility to a moral treatise printed during the first half of the 18th century in Puebla. The article proposes that, in relation to its context, the text presents notable and eccentric aspects: it restricts and discredits several forms of authority, it seeks problematics and controversy instead of dogma, it rejects supernatural reality and defends empirical knowledge, it shares ideas based on doubt and reason. The article argues that these and other peculiarities are the consequence of a discourse built upon the ideas of possibility, hypothesis and exception, and which the article analyses mainly in the voice of the author and his relationship with books and writing. 
En 1728 se publicó en Puebla un libro que reúne cuatro textos con dudas y respuestas sobre la vida de los curas. Su título (o lo primero que dice su portada) es Consultas varias, morales y místicas. A veces leemos las dudas en la voz de los curas anónimos que las hicieron, a veces las parafrasea y las responde el autor del libro, un franciscano llamado Francisco Ildefonso Segura, que parece que ordenó sus cuatro consultas según su tamaño (aunque también pudo ser el impresor o el grupo de franciscanos que pagó la impresión), porque la última es de cuatro páginas, la tercera de nueve, la segunda de setenta y nueve, y la primera de ciento sesenta y cinco. Así que el primer texto es el más largo, mucho más largo que los otros tres juntos, pero no llama la atención sólo por eso y por su lugar privilegiado, sino por su tema, porque si los demás tratan de privilegios y obligaciones de curas en situaciones muy específicas, esa primera (al menos en principio) discute el caso de una beata que sufre de algo extraño.

Pero las cuatro consultas tienen mucho en común. Todas hablan de Puebla y de la actualidad. Uno de los curas anónimos dice en la última que "en estos tiempos veo practicado otro modo" del que "antiguamente se observaba" (255); la tercera menciona los dictados de un papa que recién había entrado en funciones en 1725; la segunda habla de cosas que "en estos tiempos ya no se pueden probar" (169), y aunque la primera se ocupa del caso de la beata, resulta que lo que de verdad le interesa (lo que de verdad le espanta) es una cierta "facilidad casi universal que hoy se usa" (70).

A todas las consultas también les importa complacer. Segura nos dice que "señores doctores, curas, y pastores de almas" (xVI) le dieron apoyo económico y motivación para publicar su libro. Más adelante vuelve a decir que "algunas personas, oyendo mis razones y haciéndome favor, me instaron a que escribiera todo lo que sentía y siento sobre el punto" (167). El cura anónimo que buscó su ayuda en la primera consulta (y aquí podríamos comenzar a explicar por qué es tan larga) le suplicó que "no me abrevie la respuesta, sino que me la amplíe con todo espacio y empeño" (6). Segura le hizo caso y además se sirvió de la súplica para repetir 
Pag. is

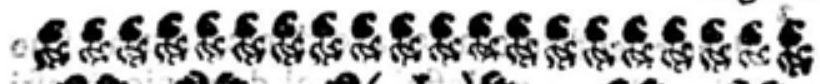
- क्ष

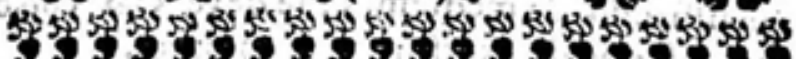

\section{CONSULTA}

Primera.

N. LONA R. P. MAESTRO: 51) tengo en efta Ciudad baftan-

1. . . tes amigos doctos, à quieries

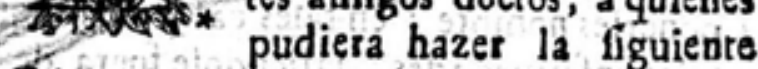

Confulta de guienes pudiera efperat el que

- por amigosquifieran, y cono doclos pudieran Catisfacer fuficientemente a la Confulta ; pero como el Medico, Confeffor, y Confuleado, dicen ha de for conformo a la inclinacion, y la 2. mia fiempre ha fido a V.P. por tanto dexando de confultar â otros, recurro à V. P. con las dudas figuientes.

N. 2. He leido en el P. Remigio, en 12 practica de Exorfifmos que quando defpues de - aver curado largo tiempo à vo enfermo, fin dàr mueftras de algun alivio, diciendo los Medie

a Cos, que no alcanzando tan buenas medicinas es incurable el enfermo, en $\mathrm{tal}$ cafo, dice el $\mathrm{P}$. Remigio, fe deve hazer juyscio de que lo que A pade-

Consultas varias, morales y místicas, resueltas por el R. P. Fray Francisco Idelfonso Segura, 1728, acervo digital de la Biblioteca Franciscana de San Pedro Cholula. Disponible en línea: catarina.udlap.mx 
comentarios como este: "Se me ofrece decir lo siguiente, por darle gusto a V.P.M.R. en ser lato" (129). Pero hay otros motivos detrás de esas ciento sesenta y cinco páginas, como por ejemplo que Segura no sólo se dedicó a obedecer sino que por su propia cuenta, preocupado por la actualidad que permea a sus cuatro textos, consideró que había que extenderse para hablar de casos como el de la beata, pues "la materia por su naturaleza, y más en estos tiempos, pide ser difusamente tratada" (8). Este es el último punto en común de todas las consultas o al menos el último que hay que mencionar de una vez y que apenas se vislumbra: la determinación personal y la curiosa maleabilidad expresiva que emerge, que aparece de repente en la voz de esos cuatro textos, aunque los últimos tres sean casi por completo revisiones de ordenanzas religiosas: "Quiero por fin darle otro golpecito al papel del dicho reverendo padre, quien formando dubio dice las palabras siguientes..." (227).

El asunto es que esa maleabilidad o ese raro protagonismo no sólo aparece mucho más en la primera consulta, sino que se desarrolla hasta construirla casi toda y volverla realmente distinta, tanto en su tamaño como en otros aspectos que tal vez no son muy fáciles de hallar en lo que nos ha llegado de la prosa impresa de la primera mitad del siglo XVIII en la Nueva España. Quisiera rastrear y compartir aquí algunas de las consecuencias de esa voz que llevó al texto, entre otras cosas, a mantener una relación un poco espinosa con la autoridad, a problematizar en lugar de reiterar certezas (como muchos de sus compatriotas hacían, habían hecho y harían en el mundo de la imprenta en español), a rechazar la sobrenaturalidad con una mesura considerable, a poner en relieve el pensamiento individual, y a evidenciar en su autor una relación peculiar con la escritura. Pienso que en gran medida todo lo anterior (incluyendo la voz del texto) es el resultado de un discurso basado, en especial, en la hipótesis y en la excepción, pero también en el enojo, que trataré de volver visible. Sólo he podido encontrar unas cuantas menciones (más bien secundarias) de las Consultas varias en estudios. Es probable que no haya muchas más o que estén algo escondidas. ${ }^{1}$ Por eso la primera parte

1 Alfonso Méndez Plancarte (Crítica de críticas, 1982), Octavio Paz (Sor Juana o las trampas de la fe, 1982), Martha Lilia Tenorio junto con Antonio Alatorre (Serafina y Sor 
de este artículo se dedica a delinear lo que dice la primera consulta y la segunda parte se encarga, con más detalle, de cómo lo dice, para ofrecer al final una lectura de algunas encrucijadas y méritos de ese textillo que sólo pudo aparecer ahí, dentro de un libro que lo mezcló con otros discursos menos raros para su contexto. ${ }^{2}$

Empecemos entonces con el qué dice. La primera consulta es un texto donde un cura, desconcertado por las enfermedades casi diarias de las beatas bajo su cargo, le escribe a Segura para contarle el caso "extravagante" de una virgen de veintitrés años, de complexión "sanguina" y entendimiento "vivo, agudo, presto, ilustrado con la lección de muy buenos libros" (3), que inició su vida conventual hace un par de años y que al poco tiempo, casi de inmediato, comenzó con una "pasión" que nadie puede aliviar, explicar, nombrar y que (para nuestra sorpresa) sólo tiene dos síntomas: hace que la beata pase días sin comer y que sufra de unos delirios verbales que el cura describe con amplitud (con escándalo):

[Habla] con gran alegría, presteza y sutileza de lengua, las cosas que dice son agudísimas y profundas, mezclándolas con algunas jocosidades, aunque no indecentes, pero sí muy graciosas, y esto sin orden, colatia, ni concierto, y mientras le dura esta pasión, a todos, aunque sean personas de gran respeto, les habla de tú, y les dice mil llanezas; y cuando menos se espera, de repente se pone en gran serenidad, y hace distinción de las personas de respeto con quien habla, y comienza a razonar con gran peso de razones y solidez de discursos (4-5).

Juana, 1998) y Margo Glantz ("El elogio más calificado", en Ensayos sobre literatura colonial, 2006), han mencionado a Francisco Ildefonso Segura, pero sólo como participante de la polémica que provocó la Carta Atenagórica de sor Juana. Circe Hernández ("El baile divino en las visiones de la Gloria en el convento de las carmelitas descalzas de la ciudad de Puebla [1630]", en Doctrina y diversión en la cultura española y novohispana, 2009) examina las Consultas varias para extraer ideas en torno a la moral impuesta a las religiosas poblanas durante el Virreinato.

2 La imprenta que publicó las Consultas varias fue la Viuda de Miguel de Ortega Bonilla, situada en el Portal de las Flores en el zócalo de Puebla. Para 1728 esa imprenta estaba a cargo de Manuela Cerezo y era la única en la ciudad con permiso para publicar actos, sermones, convites de entierros, y otros papeles de servicios y relaciones de mérito (Hernández Sautto: 206-219). Hoy en día las Consultas varias están disponibles (al menos) en la Biblioteca José María Lafragua (BUAP) y en el acervo digital de la Biblioteca Franciscana (UDLAP) de San Pedro Cholula: catarina.udlap.mx 
Pero la beata no está pálida ni enfermiza, no presenta anomalías en su orina o en su complexión, ni ninguna otra señal de alarma. Por eso la conclusión de los médicos y de los "religiosos doctos" es que sufre de un mal sobrenatural, provocado por el mismo Dios, y como no hay ningún otro síntoma que estudiar, los doctos estudian los delirios verbales: "lo que habla aun cuando delira son cosas espirituales, y lo que habla cuando está en juicio no es con estilo vulgar, sino con gran solidez, inteligencia, y alusión a lugares de la Escritura" (5-6). Pero entonces nos damos cuenta de que además de las palabras, en el relato del cura son importantes los libros, porque no sólo la beata es una gran lectora, sino que su aturdido confesor no parece tan aturdido por los delirios de ella como por sus propias lecturas, es decir, por las cosas que él mismo ha leído buscando respuestas: prácticas de exorcismos, prontuarios, directorios místicos, vidas de santos. En sus palabras, vemos que la lectura aparece antes que las enfermedades: "Por estas cosas que he leído me he hallado con algunas dudas acerca del juicio que debo hacer de varias enfermedades que algunas de mis hijas padecen con diuturnidad" (2-3). El cura, más bien convencido por el diagnóstico de los doctos, finaliza su consulta solicitando "reglas para probar espíritus" (6) en general.

Después de estas cinco páginas la voz de Segura interviene, pero en lugar de ir al grano se dedica, durante un párrafo prolongado y medio lírico, a explicar cómo ha decidido abandonar la mística para siempre, cómo sus muchas lecturas y su larga experiencia en el confesionario lo tienen abrumado:

Con distinto corazón y ánimo se arroja al mar el que nunca ha navegado, que aquel que ha atravesado los polos, corrido por las líneas sin llevar derrotero fijo, que ha naufragado en lo inconstante y furioso del elemento de las aguas [...] mientras más fui estudiando en los libros místicos y practicando en el confesionario, y más advirtiendo lo oculto de las sendas, lo inconstante de la naturaleza humana, las intempestivas mutaciones que causan sus pasiones, los vagios [sic] de la ignorancia afectada, los escollos de la vana confianza [...], el conocimiento de los yerros y perdiciones que pueden ocasionar todas estas cosas me ha puesto en extremado temor de ejercer el oficio de piloto (6-7).

Aun con su temor, Segura está obligado a responder y nos presenta esa obligación, que es el resultado de la intimidad misteriosa que lo enlaza 
con el cura, como una auténtica tragedia, pero justo después, al final del drama, aparece el juicio personal de Segura, que añade que "en estos tiempos" urge examinar "difusamente" la "materia".

Para comenzar, Segura distingue y define varias veces los tipos de enfermedades posibles en general, es decir, las naturales o causadas por la naturaleza, las preternaturales o causadas por desórdenes de los demonios en la naturaleza, y las sobrenaturales o causadas directamente por Dios y que por ello son las más raras y que, por alguna razón, abundan en Puebla desde hace un tiempo junto con las preternaturales, que les siguen en rareza. Segura compara casos del "hoy" con los del "pasado" para mostrar que los médicos y los místicos de sus días llaman "sobrenatural" a cualquier padecimiento de beatas y beatos, un diagnóstico que ni siquiera es común en las vidas de santos aprobadas por la Iglesia. Si san Francisco de Asís viviera en la actualidad, plantea Segura, viviría muy mal o viviría muy poco, porque no habría un solo docto capaz de darle medicamentos para sus calenturas, inflamaciones, tumores de hígado, dolores de ojos y el resto de enfermedades que soportó, enfermedades naturales por donde se les vea. El problema es que no cualquiera puede padecer sobrenatural o preternaturalmente. Se trata de un privilegio, de una concesión de Dios para las almas perfectas que requiere muchísimos filtros de virtud que los doctos del "hoy" ignoran o que al menos no se toman en serio. En el hoy no se acaban los exorcismos innecesarios ni los trastornos extravagantes. Sin duda la culpa es de los peritos, pero también de los pacientes. Los primeros se aturden muy fácilmente ante fenómenos tan corporales como la menstruación, y los segundos (sobre todo las beatas) exageran sus males y su devoción, simpatizan con la moda, quieren llamar la atención; en pocas palabras, se entregan a ese irreprimible y condenable mal de la naturaleza humana que es el amor propio y que despierta la competencia entre las beatas y la malicia en los que leen textos místicos, Ilevándolos a engañar a sus confesores imitando el lenguaje de Dios.

Las críticas desplazan el caso concreto del cura hasta la mitad del texto, donde Segura concluye, después de una larga exposición de pruebas, que el mal de la beata es natural y que es pura inestabilidad de humores. Pero uno no puede ignorar todo el alegato que va antes de ese diagnóstico. El montón de críticas sugiere al menos otro escenario: la beata, tal vez, es 
uno de aquellos falsos enfermos sedientos de notoriedad. Esta hipótesis es muy coherente con lo que sabemos del caso por el propio Segura. La beata está en muy buen estado de salud y no tiene otro síntoma salvo esos periodos sin alimento que podrían fingirse sin mucho esfuerzo escondiendo la comida, como argumenta Segura. Lo que la beata tiene son muchos libros, un entendimiento "ilustrado", un confesor aturdido por sus propias lecturas, "gente de respeto" que la rodea durante sus recitaciones estrafalarias de fragmentos bíblicos, y otras beatas que también la rodean y que padecen casi lo mismo "con diuturnidad". Aun así, Segura no ofrece este escenario como dictamen. Lo deja entre líneas.

Por último, se encarga del renglón donde el cura le pide reglas para probar espíritus en general, un reglón que "siendo uno, contiene infinitas dificultades" (96). El tema le sirve para hablar más sobre la plaga de falsos virtuosos de Puebla, para hablar de las beatas y beatos que observa en su día a día, en medio de su aparente humildad, simulando conseguir aplausos para Dios cuando los quieren para ellos, los que llenan de adornos sus propios oratorios pero nunca los templos de todos, los que adquieren virtud para endiosarse, los que aseguran haber visto las almas de personas que vivieron en alta dignidad pero jamás el alma de algún pobre enfermo desconocido, los que pronuncian castidad pero siguen la moda superflua, costosa y vana de la vestimenta europea. " ¡Y con todo eso", exclama Segura, sorprende que "haya algunos padres espirituales que a los que así viven los tengan por virtuosos!" (147). Acusa a los pilotos ineptos del "insondable, proceloso y arriesgado mar del gobierno místico de almas" (7) que incitan los vicios de sus hijos espirituales, a veces sin quererlo. Acusa a los curas que sólo admiten ricas en su confesionario, a los que se colman de beatos y beatas en lugar de ser juiciosos y atentos, a los que hacen públicas las extravagancias místicas de sus hijos espirituales sin pensar en los riesgos de soberbia. Luego habla de los criterios que un verdadero cura debe seguir para impedir que el amor propio de sus beatos (pero también el suyo) se apodere de sus almas. Esos criterios se reducen a una extrema cautela, sobre todo con las mujeres, porque todo padre es hijo de Adán y, por lo tanto, todo amor a sus hijas puede sepultar su entendimiento. Después Segura se despide: "Dios por quien es nos asista en tantos riesgos" (165). 
¿Cómo es la voz de Segura? Lo que uno llamaría su "expresividad" se reduce en el resto de las consultas a esos guiños que se ven de cuando en cuando. En la primera no son más que una parte de todo el involucramiento de una voz con momentos de sarcasmo ${ }^{3}$ y de patetismo, ${ }^{4}$ que maneja el texto con frases espontáneas, ${ }^{5}$ que se sirve de vocablos despreciativos retorcidos y punzantes que rebasan por mucho a los laudatorios en cantidad e inventiva (moña, embeleco, hazañero, denguero, torería, mochería, embelequillo, muchachería, celito, pleitecillo, cosilla, modito) y que se dirigen en su mayoría contra las beatas: "Tienen muy radicada la [semilla] de la cizaña, de envidia, y emulación, con muchos celitos de si el padre espiritual quiere a las otras hijas [...]. De estas y otras cosillas mujeriles continuamente se levantan pleitecillos" (114). Pero no sólo contra las beatas. Segura ataca a los escritores anónimos de "genio novelero", "misteriosos y amigos de extravagancias", a los "fáciles que se usan el día de hoy", a los falsos virtuosos, "voluntariosos, bachilleres, caprichudos y muy apegados a su dictamen" (134).

Pero hay que buscar el carácter de su voz más allá de la expresividad, en las formas que se entrometen en sus frases de principio a fin, y sobre todo hay que señalar una palabra que aparece en sus definiciones de los padecimientos humanos y que se apropia de las esencias expulsando al verbo que uno esperaría ver en una definición, el verbo ser. Ese impostor es el verbo poder:

No se puede negar que se pueden padecer enfermedades sobrenaturales, ordenadas inmediatamente por Dios, sin que se hallen, ni las haya causas naturales de donde procedan ni puedan proceder, y así se les llaman sobre la naturaleza. O pueden padecerse enfermedades preternaturales, ocasionadas por maleficio de los demonios, las cuales al juicio humano no se les halla causa, pero la tienen, y el demonio la conoce y la aplica; pero esto no es de orden común, aunque es natural y por esto se dice preternatural (8-9).

\footnotetext{
3 “¡Oh, dichosos siglos los nuestros, en que las más de las almas virtuosas son perfectas y santas!" (47).

4 "¡Oh pobres confesores, pues hallándose jueces han de dar la sentencia por lo que se les dice!" (100).

5 "En todo hallo causa natural para lo que padece, y si no vámoslo mirando uno por uno" (60).
} 
Más adelante, Segura nos deja claras sus reservas hacia el verbo ser, que encarna su aversión a la facilidad: "Si Dios lo puede hacer, no es cierto que lo haya hecho con cualquiera de las almas que hoy se usan, pues va mucho del posse al esse" (25). En el mismo párrafo hay otros favoritos de Segura que no hay que perder de vista: las conjunciones y preposiciones adversativas. Uno descubre que las frases de la primera consulta se enlazan, con una recurrencia asombrosa, gracias a la oposición:

Aunque en todo el mundo ha habido grandes yerros y engaños en esto de apariciones de muertos, pero he oído a algunos noticiosos de leyendas y discretos notar el que esto es con más frecuencia y facilidad en este Reino, y dan por causa la piedad y docilidad del criollismo; pero lo que en esto he notado son dos cosas [...] (129-130).

La confrontación sobrepasa la sintaxis. Lo que sigue después de notar lo anterior es detenerse en las ideas, en los dos perfiles de Segura que conviven dentro del texto: un clérigo contrarreformista y un crítico moralista aterrorizado por una cierta "naturaleza humana" que conoce muy bien. Los perfiles no son incompatibles, pero veremos que no tienen el mismo peso en las tesis centrales de la primera consulta, tesis que deben todo a ese discurso de la posibilidad, del puede, que domina el texto y que podemos detectar desde los verbos y las conjunciones de arriba. Tratemos primero de hacer visibles a los dos Seguras.

El primero es un buen católico, pero también una voz abatida por el mal. En sus palabras Dios es una majestad remota y solitaria. Sus ángeles, arcángeles, serafines y demás miembros del coro celeste han abandonado el mundo. La divinidad es innegable, por supuesto, pero se encuentra tan cristalizada como los padecimientos sobrenaturales, reducidos a un estado en que tan sólo no se pueden negar: "Las sobrenaturalidades no se han de negar ni yo las niego con absoluta y rebelde incredulidad, pues confieso el poder sobrenatural de Dios; y así no se han de negar ni conceder con facilidad, sino con examen prudente y cauteloso" (67). "Yo no niego ni puedo negar", dice después, "que hay Purgatorio y que algunas Almas que están en él pueden venir a pedir sufragios; pero estas son muy pocas y raras" (132). Lo mismo con los santos y los aparecidos de verdad: 
¿Habrá hoy un tan fácil, no digo ya un conjunto de tantas personas insignes en santidad como los referidos, pero siquiera habrá un místico tan insigne y santo como Santa Clara sola o como San Antonio solo, o como solo uno de los referidos? Poderoso es Dios para criarlos, pero aunque los puede criar tan místicos y más que los referidos, no tengo noticia que al presente los tenga criados (16).

La presencia rebosante de Dios en aquel pasado lleno de cosas que ya no suceden se contrapone a la actualidad, donde Lucifer se comunica con una frecuencia terrible, donde sus secuaces amenazan a cada minuto. Nuestro desencanto con el Segura clérigo llega, precisamente, cuando el diablo y compañía se convierten en el punto final de sus discusiones y concluye, por ejemplo, que se debe frenar el exceso de exorcismos porque Satanás se burla de que lo conjuren en vano, que los falsos endemoniados consiguen engañar (para nuestra sorpresa también) porque cuentan con ayuda demoníaca, que el Demonio es causa indirecta de la complicación de muchas enfermedades, que la facilidad con que los confesores incautos dictaminan obsesión en sus hijas es una trampa del Demonio, que la dificultad de la vida cristiana y de la administración sacramental en la actualidad se debe a la crecida "ciencia experimental" de los demonios, que hay que ser incrédulos con las apariciones porque puede que no sean más que ficciones demoniacas para suprimir las oraciones y sufragios para las almas del Purgatorio que realmente los necesitan. En fin, la soberbia, la codicia, los errores y desdenes de los confesores, la rivalidad de las beatas, las lecturas indebidas, la ignorancia médica y la superstición popular, o cualquier otra cosa, sólo son problemas para este Segura si provocan la perdición de las almas, problemas que vienen del más allá y que por lo tanto tienen soluciones teológicas: el Demonio, por definición, no puede fingir obediencia ni humildad, y por lo tanto, los curas deben supervisar que sus penitentes cumplan a fondo estas dos virtudes y así nunca serán engañados.

El Segura moralista ve otras cosas. Los problemas surgen, se complican y resuelven en las acciones humanas. Este Segura tiene una respuesta quizá un poco vaga, pero muy terrenal para explicar por qué es tan difícil administrar los sacramentos en el hoy: 
Habiendo crecido más y más la codicia o de bienes temporales o de adquirir honra y fama, y habiendo crecido más y más la habilidad y sutileza en los discursos, se sigue el temer con más fundamento el día de hoy el que valiéndose de la mayor habilidad que hoy se usa puedan algunos hijos espirituales formar más y mayores engaños para solicitar en sus Padres espirituales el que les busquen dádivas y socorros temporales o les fomenten y soliciten aplausos vanos y espirituales (98).

Para el Segura moralista no es suficiente la teología. Hay que ser estrategas, someter las pasiones y el amor propio mediante la razón. Una de sus estrategias podría haber sido el epígrafe del libro:

y aun siendo el enfermo médico, lo que le importa es llamar a otro médico que lo cure y haga juicio de lo que padece; porque aunque el paciente es médico puede su amor propio hacerle errar en el juicio del accidente (80-81).

Para el moralista, convencido de lo anterior, es peligroso limitarse a las confesiones. Segura llama a sus colegas a verificar las palabras de sus penitentes con informes de otros, como buen inquisidor:

pues en el informe del hijo siempre se debe oír como de parte apasionada, y en los otros no está tan cierta la pasión con que pueden informar contra él; fuera de que si uno de los informantes puede tener pasión, no la han de tener todos (107).

Este Segura dilucida sin el más allá. Sus ideas pertenecen al mundo de lo inmediato, son frutos del aprendizaje: "en la larga ficción no es posible guardar uniformidad sin contradecirse; por cuanto el que finge engañándose en su misma malicia solo va mirando para adelante" (106). Este Segura considera la practicidad del ahora, le interesa más la perfección que la salvación, y aunque el Demonio esté detrás de alguna enfermedad, permanece como propulsor secundario e insignificante en la práctica, porque se le puede combatir con lo mismo que usa: la naturaleza.

Aun si el clérigo y el moralista ocupan una cantidad más o menos idéntica de frases dentro del texto, no hay tanta igualdad en las ideas, porque la primera consulta tiene una tesis central, que es la primacía de lo natural, y que le pertenece al Segura moralista, una voz que ha pasado por un terrible desengaño: es imposible que el entendimiento, por su flaqueza 
humana pero también por estar amenazado día a día por el amor propio y la "vana confianza", abarque la totalidad de la naturaleza, "inconstante", "intempestiva" y cargada de "mutaciones". Uno percibe esta inquietud en la visión del Segura clérigo también, donde el Demonio es "el que sabe", el que conoce y usa con malicia todo lo que ignoramos. En el fondo, la primera consulta es un texto de urgencia práctica, más cercano a la sabiduría (al temor) que a la revelación. Le importa que los médicos y los místicos de su tiempo, pero sobre todo de su ciudad, pongan su atención y su esfuerzo en descartar primero cualquier mal causado por esa naturaleza inabarcable y terrenal en sus pacientes (beatos o no) y una vez descartada (si se puede) entonces ya considerar otras explicaciones:

Pues no afirmo ni defiendo que todas las vidas que se han conservado y se conservan después de largas abstinencias se hayan conservado y se conserven naturalmente: lo que solo digo y defiendo es el que cabe en lo natural dicha conservación (67-68).

Los curas y médicos que rodean a Segura parece que no conocen (si puede permitirse la expresión) el mundo de lo desconocido. Por eso viven en los extremos, en lo fácil: "Algunos ven en los enfermos, y especialmente en las mujeres, algunas extravagancias que no caben en la común serie de la naturaleza, hasta donde ellos Ilegan con su conocimiento, y aturdidos luego al punto se las atribuyen al demonio" (33). Segura no sólo es clérigo sino humano, y como tal se incluye en este error común y en muchos otros. A veces su autoinclusión es tenue pero palpable:

Pues por muy estudioso y sabio que uno sea en especular las causas segundas, es evidente que no las puede comprender todas, y así, aunque en algunos casos no se le halle causa segunda a algún efecto, no por eso puede asegurar que no la tiene (28).

Otra razón por la que el Segura moralista (que por momentos también parece filósofo) supera al clérigo es porque es él quien por fin responde a la consulta, y cuando lo hace, cuando explica los delirios verbales de la beata, ofrece una auténtica autoinclusión: “...ordinariamente nos sucede a todos; a veces estamos tardos en el discurso, la memoria como embelesada, y la len- 
gua entorpecida; $y$ en otras ocasiones, con gran agilidad, discurrimos, con prontitud nos acordamos, y con expedición hablamos" (87). La experiencia, las lecturas y la razón han convertido a este Segura en un incrédulo azotado por la condición detallista de la vivencia, cargada de actitudes minúsculas, de diminutivos: "he visto con el dolor de mi corazón ir una persona ya derecha a comulgar y hablar contra la honra del prójimo en cosas graves y ocultas; y lo mismo he visto hacer a otras acabadito de comulgar" (145).

Lo posible y la excepción permiten que los dos Seguras convivan. A veces los vemos uno junto al otro, explicando un mismo problema desde el Demonio y desde el amor propio, o al revés: "por saber tanto el demonio, puede con astucia y malicia contrahacer y remedar la locución de Dios, aunque no en el todo; y esto propio pueden también hacer los hombres" (77); "los mismos penitentes sin voluntad suya pueden ser engañados con sugestiones del demonio para que sin querer engañen a sus confesores, o los mismos penitentes, por ser hipócritas, pueden de intento querer engañar" (143). Pero el léxico del mundo empírico se adueña del diabólico y le quita espacio en los párrafos:

Se pone [el padre espiritual] a campal desafío de ciencia y experiencia con la ciencia y experiencia de los demonios: bastaba advertir que se pone a lidiar a brazo partido con la naturaleza humana, cargada de resabios, ardiles, celadas, que sin intención deliberada de engañar a sabiendas de malicia usa solo por naturaleza: bastaba saber sobre todo esto que ya ha sucedido y que puede volver a suceder (161).

Con todo y sus diferencias, el clérigo y el moralista producen juntos la singularidad de la primera consulta. El primero también se incluye en sus diagnósticos, como cura imperfecto:

Quitando los ojos de otros confesores, y solo poniéndolos en mí, me confundo y me avergüenzo, y pido a Dios con veras de mi corazón perdón de lo que en esta parte hubiere errado, inclinándome más a confesar a los ricos o a los conocidos que a los pobres o a los no conocidos: y aunque en esto por la misericordia de Dios no me reconozco tan defectuoso como en otras pasiones y miserias mías, con todo, hago propósito firmísimo y le doy palabra a Dios que en caso de aprieto [...] primero he de confesar al pobre humilde, aunque sea esclavo, que al rico... (160). 
Ambos comparten la aversión a los extremos, la consideración de las excepciones, la búsqueda de la mesura. Ambos son tan cautelosos que caen en el extremo:

pero es tanto lo que me han abierto los ojos las experiencias que aun juzgo por pocas las cautelas que expreso respecto de las que reservo: tengo creído que si en algún extremo no se da vicio es en el extremo de la vigilancia y cautela que debe tener un padre espiritual; porque contra un extremo de riesgos, peligros y ficciones es necesario otro extremo de temores, cautelas y habilidades (161).

De esta cautela extrema, de la entrega de Segura a "entresacar la cizaña de lo falso de entre el trigo verdadero" (162), viene mucho de su vocabulario: juicio, razón, saber, entendimiento, acierto, diferencia, reflexión, regla, persuasión, probar, probable, advertir, errar, errado. También le debemos el léxico que designa lo confuso o lo engañoso (misterio, misterioso, facilidad, extremo, ligereza, artificioso, fingido, ficción, sutileza, sofistería, hipócrita), la búsqueda y la ofuscación de la verdad (malicia, cautela, habilidad), y los binomios que atraviesan el texto: general-particular, cierto-falso, pasión-razón, vicio-virtud, y el más importante o el más característico, facilidad-dificultad. Otro binomio podría ser lo frecuente y lo sensacional, que vemos en términos como ordinario, extraordinario, ruidoso, extravagante, común, ridículo, conocido, nuevo, novelero, novelería.

Segura ha visto pocos médicos y pocos peritos morales y místicos tan abrumados como él. En general desconfía de ellos, desacredita sus dictámenes y su autoridad:

En caso que veamos a alguna persona virtuosa padecer algunos accidentes extravagantes, que al parecer de médicos peritos no se les halla causa natural, no por eso hemos de decir que lo que padece aquella persona es sobrenatural; porque para decir esto, porque los médicos lo afirman, era necesario que pudieran ellos con acierto decir que la tal enfermedad no tenía causa natural y esto no lo pueden decir porque su saber solo alcanza a lo conjetural (30-31).

Para ninguno de los perfiles de Segura es cosa sencilla someterse a los peritos. Se toman la doctitud con muchas reservas; en el peor de los casos 
piensan que es un peligro, porque están convencidos de que es engañosa e insuficiente. Sólo la cautela es arma contra la ficción: "Esto sucederá más bien mientras el padre fuere más leído y docto, pero menos cauteloso de lo que la cosa pide" (77-78). Es peculiar la relación de Segura con la autoridad, como se va viendo. Señala límites en los peritos que lo rodean, pero también los busca en los grandes nombres de su corpus, como Galeno, para fijarse en lo que no pueden decir:

El que muchas enfermedades tengan causa natural y no se conozca ni se pueda conocer la tal causa, ni por los indicantes ni por el estudio del mismo médico, lo enseña Galeno [...] y el Doctor Mercado explicando a Galeno [...] pero ni uno ni otro pueden afirmar que aquel accidente a quien no se le halla causa es porque no la tiene: lo más que dicen es que es al conocimiento y a la curación cosa difícil (29-30).

No sólo busca impotencias en los autores de su preferencia. Parece que admira a los que exteriorizan sus límites, como san Agustín:

¡Oh, qué prueba tan ardua y difícil! ¡Oh, y qué estudio y experiencia se requiere para esto y cuánto se puede errar! Tan difícil es probar los espíritus, que el águila de san Agustín, con todo su remonte, confiesa que no pudo alcanzar el cómo se han de probar... (46).

Lo mismo con Luis Mercado, el célebre médico personal de Felipe II y Felipe III, en quien Segura fundamenta muchas observaciones clínicas y a quien también aprovecha para asemejarlo a sí, es decir, lo presenta como un docto que subordinó lo más posible el papel de la sobrenaturalidad en los padecimientos humanos, que se admiró ante la vasta naturaleza y que se extendió para manifestarlo:

Para tratar de las tales enfermedades el dicho Mercado gasta ciento y cincuenta fojas de a folio y todo lo reduce a lo recóndito de la naturaleza, sin que tenga parte en ello el demonio. Tanto es el juicio que hace de lo intrincado y dilatado del tratado, que antes de comenzarlo hace una insigne y devota oración, invocando a Dios y a María Santísima, para que le ilustrasen y ayudasen en tan difícil y extravagante asunto (34-35). 
Así que la cautela extrema de Segura es congruente con sus valoraciones letradas, pero también con los protagonistas de su corpus. El primero es Michael Wadding (1591-1644), un jesuita irlandés que fue misionero en la Nueva España y que firmó sus obras como "Miguel Godínez". Escribió sobre definiciones, juicios y abundantes "dificultades" de la práctica mística. El segundo es Paolo Zacchia (1584-1659), físico italiano y asistente personal de dos papas, reconocido como el fundador de la medicina legal y por su escepticismo ante la sobrenaturalidad. Le sigue Juan Eusebio Nieremberg (1595-1658), el afamado humanista, físico, biógrafo, teólogo, asceta y jesuita español que escribió sobre muchos casos de fenómenos corporales extraordinarios.

Segura inmiscuye en sus críticas algunas autoridades delicadas, como las cartas pastorales de unos ciertos "señores obispos" que son partidarios de la dificultad pero que también son extremosos y precipitados:

Al bien que hablo con hombre docto y por tanto [que] ha leído en los moralistas y en algunas cartas pastorales de algunos señores obispos en que dan doctrina a sus ovejas cuán gran estudio y trabajo ponen para discernir cuál sea pecado mortal y cuál no en la materia de trajes profanos, y por su naturaleza provocativos a lujuria. Confieso que algunos de ellos están extremosos y apretados en condenar por pecado mortal cualquier moda de galas (146).

Parece que ni siquiera los padres de la Iglesia se libran de una cierta crítica, hecha con mucho cuidado y cierta ambigüedad respecto a quién se refiere:

De la doctrina de Cristo puesta en el Evangelio sacan los Santos Padres y los autores místicos reglas para gobernar y discernir espíritus; pero siempre en lo que escriben van con gran recato y timidez poniendo reglas que sólo hacen opinión, y no evidencia, y por esto en las tales reglas, o en su inteligencia y aplicación, siempre queda el formido opinable de poder errar (96).

Hay mucha mesura en el lenguaje de Segura respecto a los elogios, como hay mucha renuencia a entregar su juicio a sus lecturas. Su relación con la experiencia no lo deja saciarse con las palabras de los ajenos sobre la realidad práctica. Hay largos fragmentos de Godínez, Nieremberg y Zacchia dentro del texto, pero sólo cuando Segura considera que no posee 
conocimiento suficiente de un área del saber. En lo que no cabe duda es que Segura nunca mete a sus favoritos ni remite su juicio a los libros sin anotar algo, sin explicar sus propias persuasiones:

Aunque he oído parlar esta regla, no la he hallado en autor alguno, y así a mí me parece arbitraria y sin fundamento. Lo primero porque fuera una regla tan extravagante que para que tuviera efecto era necesario el recurrir a que Dios hiciera un milagro [...] (139-140).

En la macroestructura de las Consultas varias, es decir, en los elementos más relacionados con lo que podríamos Ilamar el "formato" del libro, la relación de Segura con la autoridad se vuelve más complicada e intrigante. Desde la pequeña semblanza de la portada, pasando por los motivos de publicación que vimos al principio, las tres censuras y las voces de los padres anónimos, el libro produce una cierta imagen de su autor, alguien continua y neciamente requerido y apreciado. Algunas experiencias narradas por él mismo contribuyen a formar esta imagen, quizá sin querer: "Un padre espiritual, docto, hizo tal empeño conmigo para que le examinara a un hijo suyo que aunque me resistí por fin me fue fuerza hacerlo" (135). Esta imagen es intrigante y complicada porque la voz de Segura, o al menos del Segura de la primera consulta, no actúa como una voz confiada en el poder de su nombre. El texto que fabrica es una rigurosa argumentación, con métodos (entre los que cabrían anécdotas como la anterior) que parecen intentos de ganarse la legitimidad que alguien del rango y condición de su autor ya debería poseer, un autor que, muy por el contrario, hace todo por evitar ser tenido por "fácil", "confiado", "temerario", "infundado", "extremoso":

Si a alguno pareciere temeridad esto, sepa, que no es sino realidad, que me consta por especiales experiencias de particulares casos que han pasado en una inquisición. / [...] Fuera de dichas experiencias me fundo en la razón, porque habiendo leído muchísimas vidas de santos, santas, y otras de verdaderamente virtuosos y virtuosas, no he hallado en ninguna de ellas extravagancias de que hayan hecho semejantes torerías ridículas al tiempo de comulgar (38).

Descubrimos entonces que Segura es también congruente en el sentido de que no sostiene su texto en su propia autoridad, al menos no del todo 
o no de forma evidente. ¿En qué lo sostiene? Vemos que desconfía de la lectura, de los libros, de los discursos y de las palabras, trata su corpus con rigor, evidencia la dificultad en otros autores, sí, pero ni san Agustín, ni Mercado, ni Zacchia, ni Godínez, ni Nieremberg escribieron textos de fracaso. No escribieron meras declaraciones de impotencia. Los intimidados por la dificultad no son los únicos que se ganan la simpatía de Segura. Están los persuasivos también, como un predicador madrileño que pasó a la Nueva España Ilamado Antonio de Ezcaray que "prueba con ingeniosas y sólidas razones" sin caer en extremos: "allí vieran con cuánta doctitud y celo santo, sin pasarse a horrores ni estrecheces de apostólico, va poniendo una bien dilatada y clara anatomía del cuerpo de los vicios" (147). Segura se refiere a un libro de Ezcaray publicado en 1691 Ilamado Voces del dolor que era una crítica severa contra las nuevas modas de vestir en Europa y que el propio Ezcaray no tenía en mucha estima o que era una estima que no pudo o que no quiso darse a entender por las convenciones de modestia y mecenazgo en que Ezcaray publicó su libro. La claridad que Segura menciona en la cita pasada era resultado, en las palabras de su autor, de la carencia de estilo elevado y de la decencia: "Como son voces del dolor no llevan aliño alguno, van escritas con claridad. Nada tienen de áulicas, es ajena ocupación de los misioneros. Por ser claras no les falta lo modesto y decente" (Ezcaray: XIV). Pero aun así, la claridad era importante para Ezcaray: "Espada contra la profanidad es este libro, abiertas van sus hojas por lo claro" (XIV). Segura, por su parte, escogió la claridad para elogiar a este favorito y también para hablar de su propio texto, pero lo hizo sin metáforas bélicas y sin que la decencia y, sobre todo, sin que el dolor vinieran a cuento, porque Segura no se dedicó a expresar con retórica los efectos de su propia claridad, es decir, no la dio por sentada, no habló de un producto sino de un proceso. La claridad se construye en el texto, como se construye la autoridad: "Para explicarme con la claridad que deseo y resolver con la solidez que necesito, juzgo por preciso hacer las suposiciones siguientes" (Segura: 167).

Lo que esto nos muestra o lo que nos conduce a ver es que Segura está enamorado de la argumentación, pero de la argumentación escrita. Lo suyo es organizar un texto racional, inteligible, exquisito en su verdad, pero un texto y nada más. Ese amor, ese gusto, es donde Segura deposita 
la validez de su obra. De ahí el más vasto de sus campos léxicos, el discursivo: escribir, discurrir, especular, decir, apuntar, explicar, referir, responder, preguntar, filosofar, reflexionar, asentar, advertir, afirmar, negar, calificar, probar, dictamen, consecuencia, argumento, conjetura, fundamento. El texto de Segura habla de la experiencia y de la realidad, pero es también un ejercicio de relativa y sorprendente autonomía escritural, un texto que se sirve de la vista y del oído sin depender ni subordinarse a ellos porque hace algo que sólo pueden hacer las palabras: persuadir, estar persuadido y persuadir de que se persuade. Lo que Segura hace es escribir y nada más, tanto, que se permitió este comentario en la segunda consulta:

Aun con todo lo que he dicho en esta resolución, bien conozco que es imposible moral el remediar esta corruptela común; pero una cosa es remediar y otra cosa es decir uno su parecer siendo preguntado: Yo no debo ni puedo remediar cosa alguna en este caso, lo que puedo hacer ya lo hago, que es escribir mi sentir, porque me lo suplicaron: el que escribe por ningún modo compele, necesita ni obliga y, por tanto, después de todo lo que ha escrito cada uno queda libre a hacer lo que quisiere (233-234).

El oído predomina, porque el oído es medio para hablar de más discursos y aun de gracias verbales, como esta crítica a los virtuosos delicados: "Yo le oí a un docto aplicarles a este género de gentes (si no con tanta solidez literal, a lo menos con gracioso sentido alusivo) aquel lugar de la Escritura: Tange montes, et fumigabunt" (123). ${ }^{6}$ El resultado es un texto que expresa una y otra vez su suficiencia, que habla en presente sobre su propia construcción: "De esto hay muchísimo escrito en la Sagrada Escritura, en los Santos Padres, y en los autores místicos; pero a mí me basta apuntar algo para explicar cómo es regla y cómo se puede valer de ella" (133-134); "Está la dicha invocación doctísima y piadosísima, tanto, que estuve por trasuntarla aquí, y no lo hago porque es muy dilatada y no hace tanto a mi intento" (35). En lugar de llenar los márgenes de referencias (de hecho, no hay una sola) la voz de Segura las inserta en el texto mismo, indicando siempre a quienes pertenecen e integrándolas con cuidado a

6 La cita latina proviene del Salmo 144 y puede traducirse como: "Toca los montes, y humearán". 
su discurso. En lugar de repetir a otros autores, Segura se funda en ellos. Ezcaray no le parece un gran escritor porque es docto, erudito, grave, ni por sus muchísimas citas, sino por sus "ingeniosas y sólidas razones". El texto de Segura se funda en sí mismo, en sus propias partes, y así justifica su extensión: "Ya fundado en lo que he escrito paso brevemente a decir lo que siento acerca de la consulta de V.P.M.R." (55). Así que uno puede argumentar que la primera consulta no se prolonga en vano para responder al cura, pero quizá lo que de verdad importa es que el texto nos dice que no se prolonga en vano. Las consultas pueden resultarnos consistentes, pero no es cualquier cosa que ellas nos digan una y otra vez que lo son.

La voz de Segura no sólo habla de sí misma. Habla de los discursos en general, incluso de su materialidad en tanto que libros, como aquellas "ciento y cincuenta fojas de a folio" que Luis Mercado "gasta" para hablar de "lo recóndito de la naturaleza". Vemos este ojo discursivo cuando Segura examina los delirios verbales de la hija espiritual del cura: "Las cosas que se dicen teniendo sustancia y modo se han de examinar por una y otra parte: la sustancia es la cosa que se dice, y el modo es el cómo o el estilo rudo o erudito, etcétera, con que se dice" (82). También cuando Segura comparte sus escudriñamientos de los discursos de los falsos virtuosos:

Y de aquí viene el que no sólo se las cuentan [sus revelaciones] a su padre espiritual con gran facilidad y como quien cuenta una cosa muy factible, sino que también (hablo de experiencia) pasan a contarlo con la misma facilidad a otras personas que tratan de virtud, y estas facilidades bien observadas no sólo hacen sospechar, sino que como reglas evidentemente prueban ser despreciables las dichas revelaciones (129).

Otro ejemplo relevante (puede que el más relevante) es cuando Segura define la sobrenaturalidad distinguiendo entre el mundo de la práctica y el mundo discursivo, acentuando los peligros del último, porque muy seguido las palabras, como se establece en la cita de arriba, operan gracias a la facilidad:

Sobre lo dicho se debe notar el que aunque en explicar estos tres miembros se ha abreviado, más y con más facilidad se ha definido el tercero, que es el sobrenatural; pero de esa misma brevedad y facilidad resulta la gran dificultad 
de entenderlo [...] Brevemente se dice que lo sobrenatural es aquello que no depende de causas segundas; pero en la práctica conocer y señalar cuál es aquello que no depende de causas segundas, ahí está la gran dificultad (28).

Con todo y sus reservas hacia la doctitud y su amor por la argumentación propia, Segura no promueve del todo el libre uso de la razón y tampoco pone en duda la importancia de los libros y de los autores. Todo es cuestión de mesura. Critica a los padres confiados que "fiándose sólo de lo que alcanzan por su natural discurso, que cuando obra por sí solo está muy sujeto a errar [...] se cargan de hijos espirituales y pasean y parlan en lugar de registrar libros" (97). Tampoco parte de sus propias definiciones, sino que sigue en especial las de Godínez y santo Tomás. Lo que hace es partir de sus propios juicios, observaciones y opiniones. Su voz se gana el derecho de pronunciarse y refutar. Aquí es inevitable volver a la macroestructura de su texto, donde esa poderosa singularidad de alguna manera se trunca, porque si Segura tenía cosas que decir sólo pudo hacerlo bajo la forma de la solicitud. Requirió el auxilio de la obediencia, como tantos de sus compatriotas novohispanos antes y después. Pero incluso si la forma de la consulta es un modo a priori de obtener la confianza del lector, nada le quita a la voz de Segura el mérito de persuadir y de limitarse (¿de entregarse?) a escribir un texto. Hay otros méritos que se deben mencionar, para ir concluyendo.

Hay que agradecerle a Segura que dio la oportunidad a un discurso, digamos, más libre y menos libresco en su primera consulta, que por más rara que sea, sólo pudo aparecer mezclada entre otras que no lo eran tanto. Algo nos permite suponer que aquello no fue necesariamente porque Segura no quiso presentarla sola. Hay razones dentro y fuera del texto para creer en el relato de su publicación. Dentro del texto están el desprecio y el temor de la voz de Segura a la soberbia y al amor propio, que invitan a pensar que fue incitado por muchos a publicar sus escritos porque él no habría sido capaz de la vanidad de proponer su propia voz, aunque combatir o al menos dar cuenta de un mal público, un mal que ponía en juego el destino de muchas almas en la eternidad, parece una buena razón. Dentro del texto tenemos también la aversión a la ficción, que nos hace preguntarnos si acaso estamos frente a una obra escrita con la des- 
vergüenza suficiente para pronunciar tal desprecio a lo fingido siendo ella misma una sarta de voces inventadas. Nada de esto excluye que Segura no haya moldeado esas consultas reales para que se ajustaran a las exigencias de la impresión, o que no haya modificado mínimamente la petición de ese primer cura anónimo para hablar de todo lo que quería. Más bien, eso parece innegable. Pero tal vez Segura inventó esas consultas. Tal vez necesitaba esas voces. No hay que olvidar las reglas del mundo de la imprenta al que perteneció este libro, un mundo muy colectivo, un mundo de censuras, semblanzas, licencias, dedicatorias y citas donde las voces individuales debían ser algo muy raro. Sin embargo, lo que sabemos sobre Segura (es decir, muy poco) parece más bien apoyar la imagen de él que existe en su texto. La semblanza de la portada nos dice que al momento de la publicación era lector jubilado, ex visitador y ex guardián del Instituto de la Santa Recolección de San Francisco. También nos dice que la impresión del texto corrió a expensas de sus "hijos espirituales" del obispado de Puebla. Beristáin de Souza lo incluyó en su Biblioteca hispanoamericana septentrional y nos informa que nació en Puebla y que fue hermano de Nicolás de Segura, un jesuita que nació en 1676 y que fue muy aclamado por sus sermones (149). ${ }^{7}$ Lo que esto significa es que Francisco Ildefonso, cuando publicó sus consultas, era alguien que ya había terminado sus oficios, que era apreciado por una comunidad de franciscanos a los que educó, y que poseía una larga experiencia. No es posible ser exactos, pero si nació en fechas cercanas a las de su hermano (digamos, en la misma década), para 1728 debía andar entre los 50 y los 60 años. Gracias a Beristáin de Souza sabemos que además de estas consultas escribió y publicó un sermón. Sólo conservamos el título, pero es muestra suficiente de que era un texto polémico dirigido nada menos que contra sor Juana: Apología del célebre sermón del mandato del padre Vieyra contra la crítica de la Monja de México.

El segundo mérito que hay que reconocer es justamente la malicia polémica de Segura. La primera consulta se apropia de un formato de registro literario didáctico, uno de los registros favoritos de la Nueva España, y lo

7 Parece que hubo otro hermano, Miguel Segura, que también se hizo franciscano en Puebla y que apenas aparece (tres líneas) en la página 150 del tomo III de la Biblioteca de Beristáin de Souza. 
convierte en una pieza controversial hecha por una voz singular. ${ }^{8}$ Es casi un hecho que sus lectores programados son otros curas poblanos: "Hablo por si acaso este papel pasare a las manos de otros padres confesores, porque ciertamente conozco y confieso que lo que intento decir no tiene parte con V.P.M.R. ni con los más de los confesores" (Segura: 154). ¿En qué medida resulta excepcional el protagonismo del yo de Segura? Dejando claro que hablamos aquí sólo de textos escritos en español, digamos lo siguiente: nuestro siglo Xvı está lleno de textos que justificaron sus voces individuales, muy marcadas, con su conocimiento exclusivo de una realidad. En la época de Segura todavía se publicaban muchos que además de estructurarse con su yo permanecían conectados a esa realidad. Pilar Gonzalbo detalla en su Historia de la educación en la época colonial (1995) cómo tanta escritura se separó de la vivencia inmediata de sus autores cuando la sociedad letrada criolla se instaló en la Nueva España y se entregó a la asimilación con España a partir del siglo XVII:

Si los primeros textos de los teólogos novohispanos se ocuparon de los problemas derivados de la conquista, y las primeras clases de la Real Universidad fueron foro de discusión de problemas locales, pronto cambiaron los objetivos y los métodos, se impusieron textos y materias ajenos a la realidad americana y la vida intelectual dio la espalda a las circunstancias en que se desenvolvía la vida colonial. La Compañía de Jesús contribuyó eficazmente a este proceso de escisión entre el mundo de la realidad y el de la vida intelectual (353).

Pero existe al menos una gran diferencia entre las Consultas varias y esos textos del XVI, incluso entre las Consultas varias y sus contemporáneos con voces parecidas: el mundo urbano. Desde el Diario de Colón, pasando por las crónicas, los diarios, los tratados e incluso muchas de las cartas

${ }^{8}$ Como ejemplo de una forma más esperada del género de la consulta en la época, una forma más impersonal, aparatosa y didáctica, están las Consultas morales y exposición de las proposiciones condenadas por nuestros muy santos padres Inocencio XI y Alejandro VII del español Martín de Torrecillas (1635-1709). La obra tuvo varias reimpresiones, parece que la primera fue en 1683 . Segura menciona en la página 51 la consulta XIX del libro, una de las más breves, donde Torrecillas prueba que el cuerpo humano (de forma muy natural) puede engendrar "moscas, arañas, escarabajos, mariposillas, chinches, vaquillas y otros géneros de sabandijas" y sacarlos, a veces, por los oídos. 
que se publicaron o se escribieron en la Nueva España antes y después del libro de Segura, el yo marcado habló desde, sobre y quizá también gracias a territorios desconocidos. Habló sobre la ardua evangelización indígena, sobre las dificultades de la provincia, del campo, de vivir en América. ${ }^{9} \mathrm{El}$ texto de Segura exhibe su individualismo desde una de las ciudades principales del Virreinato. Es una pieza muy valiosa para cuestionarse hasta qué punto el contacto directo con los acontecimientos fue el sine qua non del yo atrevido, desafiante y sincero en la escritura impresa novohispana en español. ${ }^{10}$

El tercer mérito es la consistencia del texto de Segura. Esto se refiere, por un lado, a sus frases concisas y a sus cuidados párrafos, numerados y limitados a una idea, un ejemplo, un tema, un episodio de vida, un trazo argumentativo. Pero la consistencia también se refiere, en especial, a su extraña franqueza, a lo genuina que parece su primera consulta. Segura se autodesprecia, pero es difícil reducir lo que hace a la captatio benevolentiae. Su autodesprecio son experiencias y explicaciones personales. No requirió un mecenas que le exigiera a su texto una dedicatoria con verdadera (y de seguro exagerada) falsa modestia, como tantísimos textos novohispanos. Segura se permitió unas tranquilas y breves palabras preliminares a san Pedro, donde agradeció a los colegas que le pagaron la impresión y donde meditó, con un par de citas de la Biblia, sobre los orígenes de la moral y de la mística. Llamó "obrita" a sus Consultas varias, pero es probable que se refiriera a su poco grosor y no a una supuesta baja

9 Entre los textos de la primera mitad del XVIII pueden mencionarse el prólogo del Florilegio medicinal (1712) de Juan de Esteyneffer y el Farol indiano (1713) de Miguel Pérez. De finales del XVII está el conocido Teatro mexicano (1697) de Agustín de Betancurt y su prólogo, que muy probablemente Segura leyó: "El que con la experiencia ha llegado al conocimiento de lo individual de algunos puntos, puede sin temor hablar en ellas, y mucho mejor que algunos [...] que sólo la autoridad de la dignidad les da apoyo" (Betancurt: 17).

10 De finales del XVII está la obra de Sigüenza y Góngora, tal vez ajena a esta regla. Otro tipo de textos novohispanos de elevada individualidad son los escritos por mujeres. Hay casos remarcables alrededor de 1728: la obra de sor Juana (décadas de 1680 y 1690), un diario místico que se ha titulado De conciencia, escrito quizá a principios del XVIII por la monja Isabel Manuela (UNAM, colección Escritos de Mujeres siglos XVI al XVIII, 2016) y la Vida de sor María Marcela Soria escrita por ella misma alrededor de 1757 (BUAP, UDLAP, Diálogos espirituales. Manuscritos femeninos hispanoamericanos siglos XVI-XIX, 2006). 
calidad. ${ }^{11}$ Nada impedía hacer una dedicatoria hiperelogiosa y autodespreciativa. Por alguna razón, tal vez porque de verdad le repudiaba el artificio, Segura decidió no hacerlo. También quiso emplear pocas metáforas rebuscadas y calificarlas como tales cuando lo hizo.

Queda al menos un reconocimiento más que hacer y que de alguna manera encapsula los anteriores. La primera consulta es un texto con enlaces de oposición e hipótesis, con el modalizador poder interpuesto como articulación imprescindible, enunciador de la excepción y de los pormenores de la realidad. Lo fascinante de la consulta, su rareza de fondo, es que el conocimiento invaluable que abriga está cimentado en la duda. La voz de Segura busca problematizar antes que reiterar un determinado saber oficial, y aunque su perfil clerical termine por adoctrinar hablando de la lenta y terrible degradación de la humanidad que siguió a su pecado original (y que también provocó que Lucifer y sus armas se volvieran más equipados), la doctrina del Segura moralista parte de esa acción irreconciliable, o por lo menos ácida para ojos netamente católicos, que es la duda. Lo posible es su resultado discursivo, es la consecuencia de la desacreditación (mesurada, pero notable) de la autoridad, de los desengaños del vivir diario, de la razón y de la lejanía de Dios en que vive la primera consulta, que concibe a Cristo como un astuto y severo maestro empírico que condenó a sus sacerdotes a la separación de las palabras y las cosas:

Las razones de no haber dejado Cristo en su Evangelio prefijas y evidentes reglas son varias, y a mi parecer una de ellas es el que quiso su Majestad, para el premio o el castigo, probar a los confesores en la aplicación y fidelidad; pues no habiendo evidencia en las reglas quedan los confesores con obligación de aplicarse con diligente fidelidad a buscar lo probable, o en caso de comparación, lo más probable (96-97).

11 Juan de Torres, miembro de la Inquisición, guardián de un convento franciscano en Puebla y autor de una de las censuras (la más larga) con que vienen las Consultas varias, dio a entender con insistencia que el libro le parecía pequeño: "Ya está patente, y aunque es pequeño en su cantidad, es profundo en su enseñanza saludable" (XII); "Siendo libro pequeño, es propio del instituto seráfico" (XII-XIII); "Ya el librito está abierto, ya puede salir al público" (XIII). Los autores de las otras dos censuras fueron un cura poblano llamado Antonio de Heredia y un prior provincial dominico, también poblano, Ilamado Antonio Cordero. 
Más que un clérigo, un moralista o un filósofo, Segura es un agente de separación entre signos y realidad: un éxtasis, un delirio verbal, una convulsión violenta, una profusión repentina de citas de la Sagrada Escritura no son para él sobrenaturalidad sino signos, ya sea de sobrenaturalidad o de las muchas posibilidades que su texto quiere poner sobre la mesa. La confusión de los signos lo lleva a momentos exclamativos: “¡Ah, y cuántos errores se cometen apreciando los padres los vicios de sus hijos espirituales por virtudes!" (104). La confusión de los signos exige cautela y sospecha. ¿De qué deben sospechar los curas de esa divinidad desafiante? Nada menos que de las palabras. De ahí que los libros atraviesen de principio a fin la consulta, que haya que tratar con pinzas a los autores y a la doctitud, que Segura detecte en el aumento de "la habilidad y sutileza en los discursos" no sólo el mal de su tiempo, sino el de siempre: "El diablo no engañó a Eva por lo que veía con los ojos [...] la engañó con habilidad y sofistería de palabras" (99). Aquí emerge el perfil más amargo de Segura, es decir, el inquisidor contrarreformista, el concentrado en los peligros de la lectura:

Le suplico a V.P.M.R. no deje a sus hijos e hijas que lean en los libros que traen documentos y reglas místicas; esto no es decir que lo que en ellos está escrito es malo, y si no pregunto: cuando la Santa Inquisición prohibió por escrito que no se imprimiera en lengua vulgar la letra de la Sagrada Escritura con fin de que no la leyeran los que no profesaban letras, ¿mandó esto porque juzgó que la leyenda de la Escritura era en sí mala? (80).

Aparece el Segura que se complace en narrar sus victorias sobre falsos endemoniados que hizo terminar en castigos públicos, puede que en autos de fe: "y me desengañé de las ficciones de algunos hijos espirituales, tan fijamente, que a uno de ellos lo hice parar en la Inquisición, donde se castigó públicamente" (108). El Segura para quien el amor propio es pernicioso por sus consecuencias de exceso de conocimiento: "el entender es necesario para amar [...], con todo, por la demasía del entender puede acontecer que el efecto de entender más de lo necesario no sea el amar a Dios sino el amarse a sí" (81).

Quedan más cuestionamientos que hacer: ¿desde qué coordenada sapiencial se pronuncia la voz de Segura? Si es tan estricta ante los límites y los peligros del saber, ¿por qué sabe de todo y habla de todo? ¿Cuáles 
fueron sus otras influencias, las que no menciona? Por ahora, señalemos al Segura retraído por ese océano de "yerros" y "vagios de ignorancia afectada", al Segura que fue un católico inquisidor (y quizá habría que decir también que un misógino), pero que también fue el autor de lo que parece un texto Ileno de conflicto y de una sinceridad enigmática que quiso erradicar el pensamiento simple e invitar al complejo, un texto que gracias al "ya ha sucedido y puede volver a suceder" permitió una ligera pero singular cabida a la duda en la prosa impresa del México colonial.

\section{Bibliografía}

BeristáIn de SouzA, José MARIANo. Biblioteca hispanoamericana septentrional (1821). Vol. III. México: Universidad Nacional Autónoma de México / Instituto de Estudios y Documentos Históricos, 1981.

Betancurt, Agustín de. Teatro mexicano (1697). México: M. de Benavides, Vda. de J. de Ribera, 1970.

EZCARAY, ANTONIO DE. Voces del dolor, nacidas de la multitud de pecados que se cometen por los trajes profanos, afeites, escotados y culpables ornatos. Sevilla: Thomas López de Haro, 1691.

Gonzalbo Aizpuru, Pilar. Historia de la educación en la época colonial. La educación de los criollos y la vida urbana. México: El Colegio de México. Centro de Estudios Históricos, 1995.

Hernández Sautto, Circe. "Impresos poblanos en la Biblioteca José María Lafragua: siglos XVII-XVIII", en Graffylia. Puebla. Vol. 4, núm. 6 (2006): 206-219.

Segura, Francisco Ildefonso. Consultas varias, morales y místicas resueltas por el R. P. Fr. Francisco Ildefonso Segura. Puebla: Vda. de Miguel de Ortega Bonilla, 1728. Disponible en línea: catarina.udlap.mx [Bibliotecas UDLAP, Colecciones Digitales, Fondo Antiguo Biblioteca Franciscana, Colecciones. Consultado el 12 de mayo de 2018].

ERIC IBarRa Monterroso (1995)

Es licenciado en Literatura por la Universidad de las Américas Puebla. Se interesa en la edición, traducción, y estudio de textos de los siglos XVI, XVII y en especial del XVIII en Francia y la Nueva España. Ha publicado en la revista Crítica (BUAP). 